\title{
Engenho sim, de açúcar não o engenho de farinha de Frans Post ${ }^{*}$
}

\section{Mills for manioc, not for sugar cane}

\author{
Frans Post's manioc mill ${ }^{\star \star}$
}

\author{
MARIZA DE CARVALHO SOARES \\ Pesquisadora do CNPq e Professora Associada, Departamento de História \\ Universidade Federal Fluminense \\ Campus do Gragoatá, bloco 'O', $5^{\circ}$. andar \\ 24.210-35 - Niterói - RJ \\ marizacsoares@ig.com.br
}

\begin{abstract}
E juntando-se tantas moléstias a fome, que sobre todos é miserável modo de padecer, dias houve em que se deu de ração a cada soldado uma só espiga de milho grosso. Porque a farinha de mandioca, ordinário pão da terra, esperdiçada (sic) e despendida, entre as presentes aflições valia antes o alqueire meia pataca e não se achando agora por dois cruzados, com ser o preço tão excessivo, custava mais descobri-la do que comprá-la.
\end{abstract}

Francisco de Brito Freire, Lusitânia Brasílica

RESUMO O capítulo toma um recém-lançado catálogo das obras completas de Frans Post para pensar o processamento da cana-de-açúcar e da mandioca no Brasil colonial. O pintor holandês do século XVII viveu no Brasil de 1637 a 1644, durante a ocupação holandesa e deixou uma rica coleção de óleos e desenhos, a maior parte deles representando paisagens do Nordeste, em particular engenhos de açúcar e grandes propriedades

* Artigo recebido em: 10/10/2008. Autor convidado.

** Este texto faz parte de projeto de pesquisa em andamento e foi elaborado durante minha estadia como pesquisadora visitante do Departamento de História da UNICAMP. 
rurais. O texto se apóia em fontes escritas de época para demonstrar como as telas de Post podem nos levar a uma interessante análise sobre a produção e o consumo da farinha de mandioca e do açúcar na primeira metade do século XVII.

Palavras-chave Frans Post, farinha de mandioca, engenho de açúcar

ABSTRACT The chapter takes a recently launched catalogue with the complete works by Frans Post to argue about the technology for processing sugar and manioc in colonial Brazil. The seventeenth century Dutch painter lived in Brazil from 1637 to 1644, during the Dutch occupation of Pernambuco, and left a rich collection of paintings and sketches most of them representing the Northeastern landscape, in particular sugar mills and non-identified plantations. The paper relies also on contemporary written sources to demonstrate how Post canvas can leads us tointeresting analysis about the production and uses of manioc meal and sugar during the first half of seventeenth century.

Keywords Frans Post, manioc/cassava meal, sugar mill

\section{Os engenhos na obra de Frans Post}

Em 2006, a Editora Capivara trouxe ao público as Obras Completas de Frans Post (1612-1680). Pedro e Bia Corrêa do Lago, os organizadores da publicação e do Catálogo raisonné (1636-1680) aí incluído, fizeram um minucioso trabalho de identificação das obras, chegando a um total de 155 óleos confirmados como de autoria de Post, distribuídos em quatro fases. ${ }^{1}$ A estada de Frans Post no Brasil - e mais especialmente em Pernambuco - correspondeu ao governo de Maurício de Nassau, entre 1637 e 1644, durante a ocupação holandesa em Pernambuco (1630-1654). ${ }^{2}$ Um dos mais famosos relatos destes tempos foi deixado por Gaspar Barlaeus (1584-1648), cuja História dos feitos recentemente praticados durante oito anos no Brasil (Amsterdã, 1647) foi escrita sob encomenda de Maurício de Nassau. Barlaeus nunca visitou o Brasil e escreveu seu livro a partir de informações de terceiros. Em resposta a Barlaeus, Francisco de Brito

1 LAGO, Pedro Corrêa e LAGO, Bia Corrêa. (orgs.) Catálogo raisonné. In: Frans Post (1612-1680). Obra completa. Rio de Janeiro: Capivara, 2006, p.82-411. Ao longo do texto as obras estão identificadas segundo seu número no Catálogo raisonné, contido nessa publicação: os óleos recebem apenas uma numeração seqüenciada por ordem cronológica; os desenhos têm numeração à parte, precedida por um "D"; e as gravuras aparecem com numeração precedida por um "G".

2 Os holandeses fizeram suas primeiras investidas no nordeste no início do século XVII e se estabeleceram em Pernambuco em 1630. Sofreram sangrenta derrota na batalha dos Guararapes em 1649 e foram finalmente expulsos em 1654. Sobre Nassau e os holandeses no Brasil, ver MELLO, Evaldo Cabral de. Perfis brasileiros - Nassau. São Paulo: Companhia das Letras, 2006. 
Freire escreveu Nova Lusitânia, História da Guerra Brasílica (Lisboa, 1675). Português, almirante da frota da Companhia de Comércio do Brasil que derrotou os holandeses em 1654, pertencia a uma família de senhores de engenho da Bahia e governou Pernambuco entre 1661-1664. ${ }^{3}$

Dentre os 155 óleos apresentados no Catálogo, 34 deles são intitulados "engenhos", outros três desenhos recebem a mesma designação, num total de 37 trabalhos, alvo da atenção deste texto (ver listagem no Anexo 1). ${ }^{4}$ Segundo Barlaeus, o Brasil holandês possuía 166 engenhos, "dos quais 120 se acham trabalhando e os mais se vão restaurando anualmente para novos trabalhos". ${ }^{5}$ Já Francisco de Brito Freire informa que Pernambuco tinha 101 engenhos. Não especifica quantos estariam destruídos, mas acrescenta existirem ainda vinte engenhos em Itamaracá e oito no distrito de Sergipe. ${ }^{6}$ Mesmo considerando que muitas telas de Post reproduzidas no Catálogo sejam repetições ou adaptações umas das outras, e que o número total de engenhos mencionados por Barlaeus e Brito Freire seja apenas uma estimativa pouco precisa, estes 34 óleos correspondem a uma amostra representativa dos engenhos então em funcionamento no Brasil holandês. Importante notar que, do conjunto de 37 trabalhos, apenas um tem título na própria obra, o desenho Inghenio Maratapasipe in Brasil, 1638, que os organizadores intitulam Engenho Maratapasipe (D57). ${ }^{7}$

A metodologia adotada para análise dos quadros teve como preocupação extrair das próprias imagens as informações e a caracterização destes engenhos; para enriquecer a leitura das imagens recorri a textos de época, em especial Barlaeus e Brito Freire. Escritas a partir de diferentes pontos de vista e intrincadas em sua própria concepção, essas duas obras me pareceram apropriadas para sustentar o argumento aqui desenvolvido. Além deles recorro ainda a Gabriel Soares de Souza, autor do Tratado descritivo do Brasil em 1587, a Ambrósio Fernandes Brandão, autor dos Diálogos das grandezas do Brasil e ao jesuíta João Antonio Andreoni, autor de Cultura e Opulência do Brasil, mais conhecido como Antonil. ${ }^{8}$

Começo então pela definição do que é um engenho. Segundo Barlaeus, o engenho é a "indústria", ou seja, são as "oficinas a que os portugueses

3 Foram consultadas edições brasileiras: BARLÉU, Gaspar. História dos feitos recentemente praticados durante oito anos no Brasil. Belo Horizonte: Itatiaia, 1974; FREIRE, Francisco de Brito. Nova Lusitânia, História da Guerra Brasílica. São Paulo: Beca Produções Culturais. 2001. A grafia "Barléu" segue a usada nesta edição da obra, ao longo do texto optei pela grafia usual do nome no Brasil: Barlaeus.

4 Não considerei as gravuras para evitar o risco de alteração ou re-apropriação de elementos não pertencentes aos trabalhos originais de Post. Por fim, merece especial destaque o mapa de George Marcgraf, Brasília qua parte parer Belgis (G35) onde estão reproduzidas várias cenas dos óleos de Post, entre elas um engenho de açúcar. Ver o mapa em LAGO, Pedro Corrêa e LAGO, Bia Corrêa. (orgs.) Catálogo raisonné, p.408-409.

5 BARLÉU, Gaspar. História dos feitos recentemente praticados..., p. 125.

6 FREIRE, Francisco de Brito. Nova Lusitânia, p.119, 187, 247.

7 Perdido, pertenceu a Eduardo Prado. LAGO, Pedro Corrêa e LAGO, Bia Corrêa. (orgs.) Catálogo raisonné p.391.

8 SOUZA, Gabriel Soares de. Tratado descritivo do Brasil em 1587. São Paulo: CEN/EDUSP, 1871; BRANDÃO, Ambrósio Fernandes. Diálogos das grandezas do Brasil. São Paulo: Melhoramentos, 1977; ANDREONI, João António (André João Antonil). Cultura e opulência do Brasil. São Paulo: Companhia Editora Nacional, 1967. 
chamam de Engenhos, porque tais maquinismos e construções foram inventadas por engenhos agudos, e contam-se entre as novidades dos últimos séculos". ${ }^{9}$ Mas a palavra engenho pode também ser usada em outras acepções. No uso corrente, incorporado pelo Catálogo, a palavra "engenho" é uma designação genérica, aplicada tanto às "oficinas" ou "fábricas" de açúcar, quanto ao processo de moagem da cana, e por extensão às plantações e ao conjunto da propriedade onde se produz açúcar. Importante ressaltar que não são chamados engenhos as propriedade nas quais planta-se cana, mas não se processa o açúcar. Por outro lado, mesmo tendo como principal produto comercial o açúcar, todas se dedicam em alguma medida ao plantio de outros produtos e à criação de gado.

Existem engenhos de açúcar, mas, também, engenhos de outros produtos. Todos são engenhos porque no beneficiamento de sua produção recorrem, no dizer de Barlaeus, a "maquinismos e construções inventadas". Vale conferir a definição de engenho no Vocabulário de D. Raphael Bluteau, o primeiro de ampla circulação no Império Português: "ENGENHO. Força natural do entendimento, com a qual o homem percebe prompta, \& facilmente o que lhe ensinam, aprende as sciencias, \& artes mais difficultosas, inventa, \& obra muytas cousas". ${ }^{10}$ Entre as invenções está a "maquinaria" para a "fabricação" do açúcar e da farinha.

Por fim, num sentido mais amplo, são designados engenhos as grandes propriedades voltadas para a produção comercial do açúcar. É o caso, por exemplo, do título dado por Post ao desenho Engenho Maratapasipe (D57) que representa uma paisagem com um conjunto arquitetônico indiferenciado, onde não há qualquer indicativo de uma oficina e onde o único indício de alguma atividade econômica é uma cerca arredondada, mostrando a existência de um curral. A designação "engenho" decorre certamente do conhecimento que o artista tinha do conjunto daquela propriedade e não apenas da parte dela retratada no desenho.

A partir dos 37 engenhos identificados pelo Catálogo, organizei um quadro com quinze variáveis que foram quantificadas segundo sua freqüência e distribuição: terreno em declive; casa grande acima do engenho; água corrente nas redondezas; telhado duplo; ventilação no telhado; fogo indicativo de fornalha e caldeira; moenda; roda d'água; canaleta para escoamento da água da roda; balcão para secar, amassar e encaixotar o açúcar; canas em feixe para serem moídas; lenha para a fornalha; pães-de-açúcar; escravos na moenda; escravas carregando cana moída (ver quadro no Anexo

9 BARLÉU, Gaspar. História dos feitos recentemente praticados..., p.22. Freire fala em "notáveis oficinas a que chamam engenhos". FREIRE, Francisco de Brito. Nova Lusitânia, p.68.

10 BLUTEAU, Raphael. Engenho. In: Vocabulario Portuguez e Latino, Aulico, Anatomico, Architectonico, Bellico, Botanico, Brasilico, Comico, Critico, Chimico, Dogmatico, etc. autorizado com exemplos dos melhores escriptores portuguezes e latinos, e oferecido a el-rey de Portugal D. João V, tomo I, Coimbra, 1712. Tomos seguintes saem até 1728, em Coimbra e Lisboa. Pode ser encontrado online em www.ieb.usp.br 
2). Essas quinze variáveis englobam ocorrências relativas ao uso do meio ambiente, da arquitetura, da tecnologia e da divisão do trabalho e podem ser tomadas como indicativas de que a cena ou paisagem corresponde efetivamente ao que Post apresentou como um engenho de açúcar. Apenas duas, óleo 47 (Imagem 1) e óleo 58, cumpriram todos os requisitos. Cinco cumpriram quatorze deles; sete ficaram entre treze e dez; outras seis entre nove e seis; quinze entre um e cinco; e por fim duas não apresentaram os requisitos selecionados (óleos 14 e 31). (Imagens 2 e 3)

Nenhum dos óleos de Post mostra engenhos movidos à tração animal, motivo pelo qual essa variável não foi incluída entre as selecionadas. Segundo Barlaeus, a Paraíba, invadida em 1634, teria dezoito engenhos, "dos quais uns se movem à força da água, outros à de bois". ${ }^{11}$ Infelizmente não pude obter informação mais exata sobre esta proporção, nem para a Paraíba nem para Pernambuco. Entre os 37 engenhos do Catálogo apenas um é movido à tração animal, um desenho e não um óleo (D21 - Engenho de duas rodas movido por bois, 1650). Os demais, maiores ou menores, mais ricos ou mais pobres, são todos engenhos movidos à água. O D21 foge ao padrão estabelecido por Post e, de certa forma, faz par com o D54, movido à água, mostrando as duas alternativas tecnológicas da época. O fato de todos os óleos serem engenhos movidos à água não parece ser uma casualidade.

Falando dos primeiros anos do século XVIII, Andreoni informa que alguns engenhos têm a "realeza" de moerem com água, à diferença de outros que "moem com cavalos e bois e são menos providos e aparelhados". Ainda segundo Andreoni, os que moem com roda água são chamados "engenhos reais". Sua descrição toma como base o engenho de Sergipe do Conde, segundo ele "quase rei dos engenhos reais". ${ }^{12}$ Sergipe, Bahia, foi invadido pelos holandeses e o engenho destruído. Quando foi visitado por Andreoni já estava outra vez em pleno funcionamento. ${ }^{13}$ Andreoni forneceu a detaIhada descrição deste engenho que visitou e onde teve a oportunidade de conversar com o administrador, segundo ele profundo conhecedor do assunto, de quem obteve as informações registradas. Sua obra foi escrita entre 1681 (ano de sua chegada ao Brasil) e 1710 (ano da licença para publicação da obra), portanto algumas décadas depois da estadia de Post no Brasil holandês. ${ }^{14}$

Os engenhos do Brasil holandês devem ter sido menores que os vistos por Andreoni na Bahia meio século mais tarde, especialmente menores que

11 BARLÉU, Gaspar. História dos feitos recentemente praticados, p.73.

12 ANDREONI, João Antônio. Cultura e opulência do Brasil, p.133-134.

13 BARLÉU, Gaspar. História dos feitos recentemente praticados, p.65.

14 Ver CANABRAVA, Alice P. João António Andreoni e sua obra. In: ANDREONI, João Antônio. Cultura e opulência do Brasil, p.9-112. 


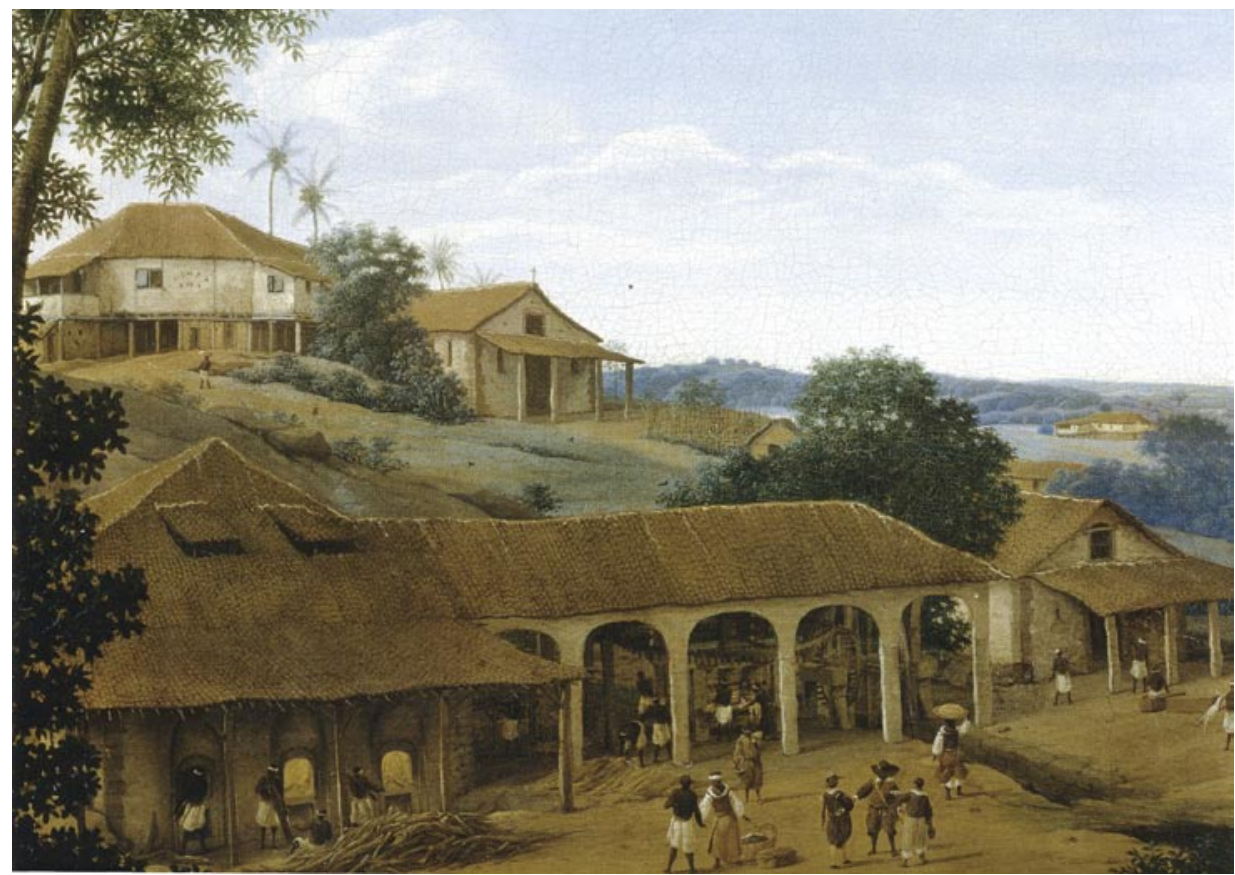

Imagem 1. Frans Post. Detalhe de engenho real. (óleo 47)

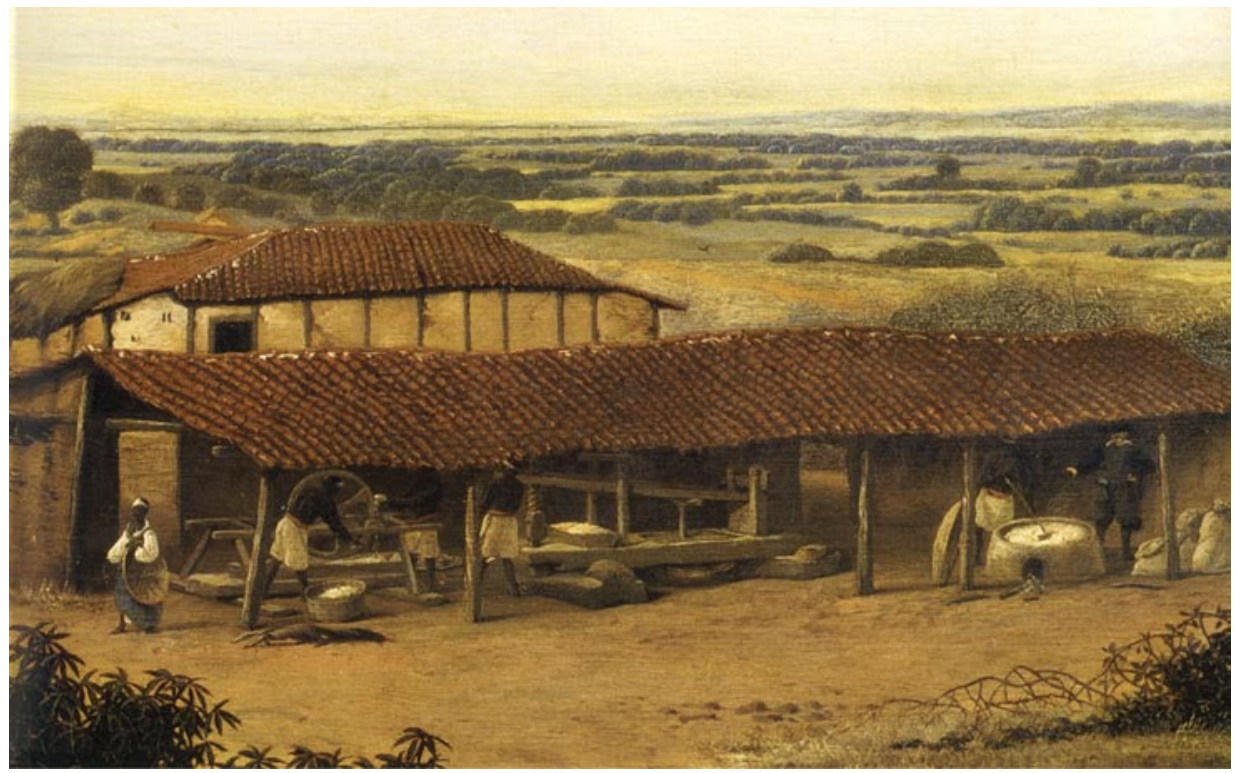

Imagem 2. Frans Post. Detalhe de oficina de farinha. (óleo 14) 


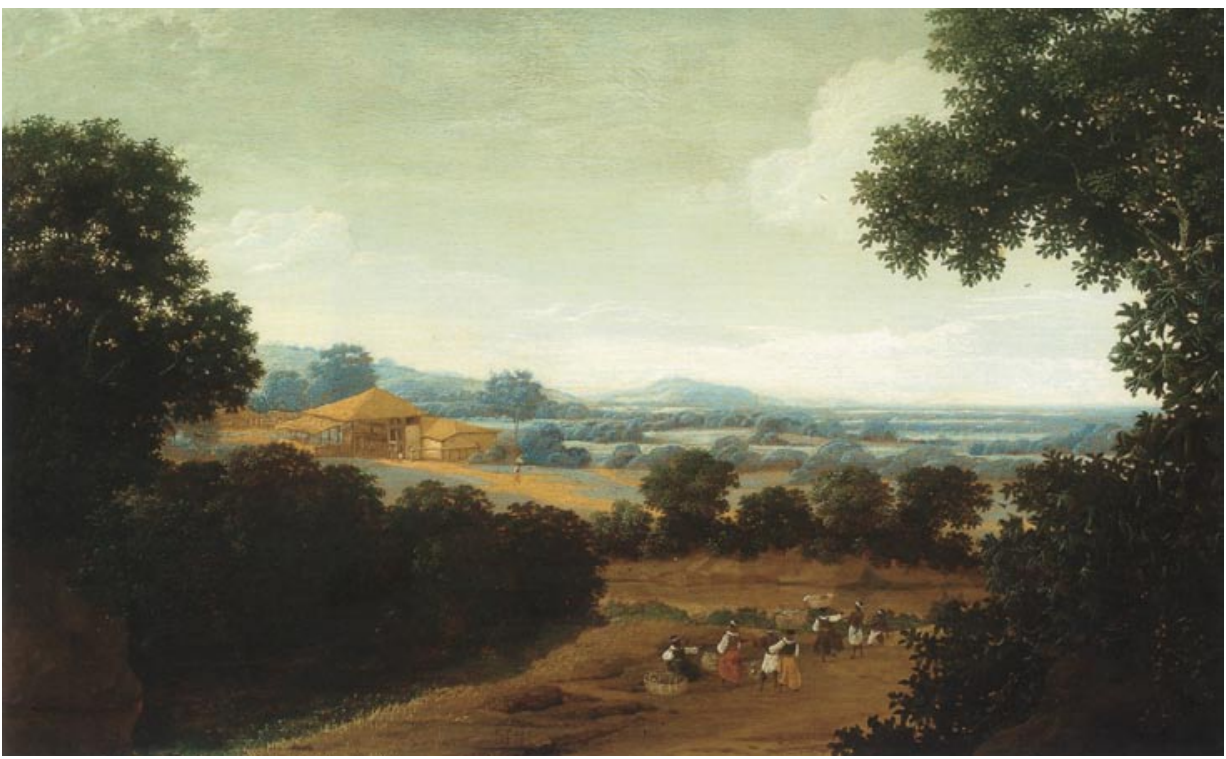

Imagem 3. Frans Post. Paisagem de várzea com conjunto arquitetônico. (óleo 31)

o de Sergipe do Conde..$^{15}$ Entre os mais antigos engenhos de Pernambuco está o Engenho Camaragibe (atual município de Camaragibe/PE), de propriedade de Diogo Fernandes, cristão-novo casado com Branca Dias que data do século XVI. Infelizmente não se dispõe de uma boa coleção de imagens de época dos engenhos de Pernambuco, Bahia e Rio de Janeiro para proceder a uma comparação apurada entre eles. O fato dos engenhos pintados por Post mostrarem moendas movidas à água, engenhos reais, é uma informação fundamental para o conhecimento, em detalhe, do funcionamento dos engenhos no século XVII. Foi nos engenhos de Pernambuco e da Paraíba que os holandeses aprenderam as técnicas de beneficiamento do açúcar depois implantadas no Caribe. ${ }^{16}$

Foram, portanto, justamente os chamados "engenhos reais" que atraíram a atenção de Post. É possível também que os cerca de cem engenhos contados por Barlaeus e Brito Freire fossem engenhos reais. Seguindo essa pista das fontes disponíveis, vou também me concentrar nos óleos de Post, portanto, nos engenhos reais.

A presença, mas, principalmente, a combinação das quinze variáveis selecionadas nos óleos de Post caracteriza um padrão do que era identificado

15 ANDREONI, João Antônio. Cultura e opulência do Brasil, p.134

16 Sobre o deslocamento da produção de açúcar do oriente até as Américas ver MILLER, Joseph C. O Atlântico escravista: açúcar, escravos e engenhos, Afro-Ásia, n.19/20, p.9-36, 1997. 
com um engenho de açúcar no século XVII. ${ }^{17}$ Por outro lado, a ausência de algumas delas pode resultar da distância e do ângulo tomado, não sendo, consequentemente, motivo suficiente para desqualificar um quadro como um engenho de açúcar. Os fundos de um engenho, por exemplo, podem não mostrar a moenda (caso do engenho 54$) ;{ }^{18}$ uma tomada lateral pode encobrir a fornalha (caso do engenho 29). ${ }^{19}$ Uma das mais completas composições de Post para um engenho real é o óleo 58: possui paisagem em declive, casa grande em nível acima do engenho com sua capela, água corrente na várzea, roda d'água com sua canaleta escorrendo pelo terreiro em direção ao rio, moenda com os escravos e canas empilhadas, a fornalha com sua lenha; e por fim, ao lado, o balcão com os escravos quebrando o pão-de-açúcar.

Uma dificuldade e mesmo impedimento na identificação das variáveis escolhidas foi, ainda, a impossibilidade identificar certos detalhes, apesar da boa qualidade da impressão. No caso da reprodução fotográfica do engenho 29, por exemplo, a visão está prejudicada pela qualidade da imagem, escurecida pelo tempo justamente no lugar da moenda. Uma única informação relevante não extraída das imagens ao longo da análise é a das mulheres com peneiras na cabeça. Essas mulheres aparecem nos engenhos 47 e 114. Segundo a legenda de Post, anexada ao desenho do engenho movido a bois (D21), elas carregam cana moída. ${ }^{20}$ Estas mulheres não devem ser confundidas com as que carregam grandes cestos nas cenas de estrada, sobre quem falarei adiante.

Terminado este levantamento foi possível chegar a um padrão no qual os engenhos reais pintados por Post se localizavam em terrenos em declive, geralmente abaixo da casa grande e da capela; possuíam água corrente captada de algum riacho - por queda natural ou realinhamento dos cursos - para ser em usada na roda d'água. Depois de passar pela roda, a água escoava por uma canaleta até um riacho próximo, e dali para um rio maior, na várzea. Por fim, em todos eles se usava mão-de-obra africana, ficando os índios para outros serviços, nos quais não vou me deter aqui. ${ }^{21}$

As chamadas oficinas englobavam dois espaços: uma parte aberta e mais retangular onde ficavam a moenda e a roda d'água; e outra fechada

17 Além dos engenhos de açúcar também os engenhos de cachaça beneficiam a cana; são também chamados "engenhocas". Ver SOARES, Mariza de Carvalho. O vinho e a farinha, 'zonas de sombra' na economia atlântica no século XVII. In: SOUSA, Fernando de. (coord.) A Companhia e as relações económicas de Portugal com o Brasil, a Inglaterra e a Rússia. Lisboa: CEPESE/Afrontamento, 2008, p.215-232.

18 Pela posição da roda, a moenda fica do outro lado. Pelo mesmo motivo não mostra tampouco os escravos trabalhando. Em compensação vê-se bem de perto o deságüe da canaleta num pequeno riacho e a várzea bem ao fundo.

19 Mostra nitidamente a canaleta e a água, mas não a roda

20 De acordo com a tradução da legenda: " 5 são as negras que levam a cana espremida". LAGO, Pedro Corrêa e LAGO, Bia Corrêa. (orgs.) Catálogo raisonné, p.379.

21 Para uma detalhada descrição de uma moenda movida à água ver ANDREONI, João Antônio. Cultura e opulência do Brasil, p.182-188. 
e mais quadrada onde se fabricava o açúcar. As duas partes podem ser reconhecidas pelo formato dos telhados e pela presença ou ausência de paredes. Todos os engenhos mostrados por Post apresentam apenas a parte externa dessas oficinas. Do que se passa no interior do cômodo fechado a única informação que se tem está no desenho 21 onde aparece uma caldeira e uma "pomba", grande colher usada para tirar o "mel" (caldo) das caldeiras, no lado esquerdo do quadro. ${ }^{22}$ Próximo a esse conjunto montam uma prancha de madeira sobre estacas, chamada "balcão" onde o açúcar e deixado ao sol. Andreoni descreve dois balcões, um de mascavar e outro de secar. Post mostra apenas um balcão em cada engenho, ao que tudo indica usado para quebrar o pão e secar o açúcar. O óleo 57 mostra nitidamente as duas atividades sendo realizadas no mesmo balcão: um escravo quebrando o "pão-de-açúcar" ${ }^{23}$ e outro empurrando o açúcar quebrado com o "rodo de camboá". Essa variação pode ser resultado de uma mudança no processamento do açúcar ao longo dos anos, já que o modo de mascavar interfere sensivelmente na melhoria do produto final e consequentemente, na elevação de seu preço. ${ }^{24}$

Por fim foram consideradas diferentes modalidades de trabalho. Uma constatação importante é que todas as oficinas têm escravos trabalhando. Não há no conjunto dos quadros qualquer indicação regular da procedência dos escravos, mas a bibliografia indica serem eles, em sua maioria, oriundos da África centro-ocidental. Um exemplo da procedência dos escravos no século XVII é o Quilombo dos Palmares ${ }^{25}$ (à época localizado na Capitania de Pernambuco, hoje Estado de Alagoas), aonde grande parte dos quilombolas vinha de Angola. ${ }^{26} \mathrm{Na}$ impossibilidade de identificar qualquer sinal indicativo da procedência dos africanos nos traços de Post, os escravos foram aqui considerados apenas do ponto de vista de seu trabalho. As variáveis escolhidas foram: homens trabalhando na moenda; mulheres carregando a cana moída. Não posso aqui deixar de indicar a presença freqüente de índios e também de escravos fora destas situações de trabalho. Índios e escravos em atitude de descanso são raros nas cenas de engenhos de açúcar. Escravos conversando ou dançando aparecem usualmente nas estradas e caminhos (óleos 30 e 38, por exemplo), indicando que o artista

22 Sobre a fornalha e a lenha ver ANDREONI, João Antônio. Cultura e opulência do Brasil, p.194-197. Sobre essa terminologia ver BARBALHO, Nelson. Dicionário do açúcar. Recife: s.e., 1984.

23 Açúcar solidificado em forma de cone que depois é quebrado para ser colocado nas caixas. Ver um balcão com pães-de-açúcar e escravos enchendo uma caixa no óleo 47, reproduzido em anexo.

24 Ver ANDREONI, João Antônio. Cultura e opulência do Brasil, p.119-121.

25 Sobre o quilombo dos Palmares ver SCHWARTZ, Stuart. Repensando Palmares, resistência escrava na colônia In: Escravos, roceiros e rebeldes. Bauru: EDUSC, 2001. Sobre açúcar, escravos e Portugal ver SCHWARTZ, Stuart. Prata, açúcar e escravos: de como o império restaurou Portugal. Tempo, n.24. vol.12, p.201-223, 2008. Sobre o comércio de escravos africanos ver PUNTONI, Pedro. A mísera sorte. A escravidão africana no Brasil holandês e as guerras do tráfico no Atlântico sul, 1621-1648. São Paulo: Hucitec, 1999.

26 Sobre Palmares ver tese recente de LARA, Silvia Hunold. Palmares \& Cucaú. O aprendizado da dominação. Campinas: UNICAMP, 2008. (História do Brasil, Tese para o concurso de Professor Titular). 
deve tê-los visto enquanto de deslocava de um lado a outro. Os índios e índias geralmente aparecem em grupo, andando ou parados. Para atrair a atenção do artista deviam existir em grande número. O engenho 114 mostra escravos trabalhando e um grupo de índios em pé, afastado da moenda; a presença de crianças indica ser uma família. O engenho 17 mostra nitidamente uma situação de sociabilidade, reunindo índios e escravos nas proximidades de um engenho. ${ }^{27}$

Dos 34 óleos, trinta apresentam terreno em declive e 31 apresentam água corrente na várzea. Entre aqueles que a distância e o ângulo permitiram conferir, foi possível identificar dezesseis moendas e dezessete rodas d'água. Somando os óleos e os desenhos, das dezoito moendas, quinze têm homens trabalhando na moenda, nove têm mulheres carregando cana moída, e treze têm canas no chão aguardando para ser moídas. Das dezessete fornalhas, quatorze tem homens trabalhando e lenha aguardando para se queimada. Das dezoito rodas d'água, quatorze tem canaletas para escoamento da água. E dos treze balcões, doze mostram pães-de-açúcar sendo manipulados pelos escravos, os demais mostram o açúcar já quebrado, secando ao sol, e por fim, sendo encaixotado (o pão-de-açúcar, o açúcar quebrado e os caixotes aparecem, por exemplo, na reprodução fotográfica do óleo 29). Treze engenhos mostram canas no chão e quatorze mostram lenha empilhada junto à boca da fornalha. Estes são, portanto, fortes e recorrentes indícios de que havia, no olhar do artista, uma grande regularidade no que diz respeito ao seu modo de captar e representar as cenas e paisagens, incorporando o cotidiano dos engenhos. Por outro lado, para além da coerência interna, seus quadros reiteram descrições escritas de época. ${ }^{28}$

Se nos 34 óleos a composição regular dos engenhos de açúcar já é por si só importante, o mais curioso é a ausência absoluta dessas variáveis em duas obras: os óleos de número 14 (Engenho, de 1651) e 31 (Paisagem de várzea com engenho, de 1656). Post chegou ao Brasil junto com Nassau em 1637 e em 1644 já estava de volta à Holanda. Segundo o Catálogo, os dois quadros pertencem à segunda fase do artista (1644-1660) e foram pintados logo depois de seu retorno. O primeiro aparece na página 128; a página 129 mostra a ampliação de um detalhe que permite ver, com clareza, a cena representada. O segundo está na página 163 e não foi feita reprodução de detalhe do mesmo, o que indica não terem os organizadores da obra encontrado nele nenhuma particularidade digna de destaque.

27 A questão indígena seja do ponto de vista do uso do trabalho indígena, seja no que diz respeito a sua inserção social na sociedade colonial como um todo é bastante complexa e extrapola os objetivos deste texto. Para maiores informações ver PUNTONI, Pedro. A guerra dos bárbaros. São Paulo: Fapesp/Hucitec/Edusp, 2002.

28 Como já foi dito acima a mais detalhada foi deixada por Andreoni, mas quase todos os textos dos séculos XVI e XVII fazem referência a eles, como mostrei no início deste texto. 
Sobre o óleo número 14 os Correia do Lago dizem tratar-se do primeiro engenho datado de Post, sendo o último de 1668. Segundo eles é um óleo sobre madeira, 47 X 68,5 cm, "até hoje inédito", assinado "F. Post 1651" sobre uma pedra localizada no meio do quadro; a obra pertence a uma coleção particular dos descendentes do artista e encontra-se na Inglaterra. ${ }^{29}$ Há, entretanto, no comentário dos Correa do Lago um engano que deve ser anotado. Segundo eles, trata-se do primeiro "engenho de açúcar" da obra de Post..$^{30} \mathrm{O}$ uso da expressão "engenho de açúcar" para descrever o quadro é pouco apropriado. Como vou demonstrar os equipamentos e as atividades representadas neste óleo não correspondem aos encontrados nos demais óleos que mostram as "fábricas" dos engenhos de açúcar.

Sobre o quadro de número 31 os organizadores do Catálogo informam ser um óleo sobre madeira, $41 \times 59 \mathrm{~cm}$, assinado e datado na parte inferior esquerda "F. Post, 1656"; a obra pertence atualmente ao Frans Hals Museum, de Haarlem, cidade natal do artista. Acrescentam ainda ser um belo quadro, com "raro reposoir duplo de vegetação densa" onde as "árvores e arbustos não apresentam as características mais especificamente tropicais que Post usará exaustivamente na década seguinte (palmeiras, coqueiros, mamoeiros, etc.)" ${ }^{31}$ O óleo 31 é um dos casos em que a identificação do engenho fica dificultada tanto pela distância quanto pelo ângulo em que o conjunto arquitetônico é retratado. Trata-se de uma paisagem na qual foi impossível constatar com clareza a presença de qualquer das variáveis recorrentes nos engenhos de açúcar. Não há declive no terreno, não há fogo ou lenha, moenda, escravos trabalhando ou qualquer dos outros indicadores.

Olhando os óleos 14 e 31 é fácil perceber que ambos os conjuntos arquitetônicos estão nitidamente localizados na várzea e não há qualquer elevação, pequena que seja em sua volta. No caso do óleo 31 o próprio título do catálogo reforça essa constatação: Paisagem de várzea com engenho. Já no 14 vê-se igualmente ao fundo, na mesma linha da casa, uma extensa várzea. Segundo os autores do Catálogo há no quadro 31 "um pequeno

29 Dentre os 34 óleos onze deles fazem parte da segunda fase e destes quinze foram datados: 14 (1651); 17 e 20 (1652); 30 e 31 (1656) 37 e 38 (1658); 45 (1659); 47 (1660); 48 e 50 (1661); 75 (1664); 76 (1665); 104 (1667) e 109 (1668).

30 Diz o texto: "primeiro engenho de açúcar completo da obra pintada conhecida de Frans Post, este óleo sobre madeira até hoje inédito é das descobertas mais importantes dos últimos 10 anos com relação à obra de Post, e enriquece indiscutivelmente nosso conhecimento da evolução da segunda fase do artista. Post aborda pela primeira vez aquele que se tornará o mais freqüente e popular dos temas da terceira fase de sua obra. Voltará a repeti-lo apenas quatro vezes e nos nove anos seguintes desta segunda fase, e somente oito anos mais tarde". LAGO, Pedro Corrêa e LAGO, Bia Corrêa. (orgs.) Catálogo raisonné, p.128 (referente ao engenho 14).

31 Diz o texto: "belo quadro com raro reposoir duplo de vegetação densa, raramente usado por Post na segunda fase, mas que ocorrerá várias vezes nos terceiro e quarto períodos. As árvores e arbustos não apresentam as características mais especificamente tropicais que Post usará exaustivamente na década seguinte (palmeiras, coqueiros, mamoeiros, etc.)". E no parágrafo seguinte, "Homens e mulheres negros provavelmente escravos, conversam animadamente... No segundo plano, a esquerda, distingue-se um pequeno moinho de cana movida (sic) a água... A paisagem de várzea será o motivo principal da grande maioria dos quadros da segunda metade dos anos 1650 e aparece aqui executada com grande qualidade, visível atrás do rio no primeiro plano, elemento raro nos quadros de Post". LAGO, Pedro Corrêa e LAGO, Bia Corrêa. (orgs.) Catálogo raisonné, p.163 (referente ao engenho 31). 
moinho de cana movido à água". ${ }^{32}$ Infelizmente não foi possível, apesar da qualidade da impressão, comprovar essa ocorrência. Por outro lado, como foi visto, rodas d'água são construídas em terrenos em declive, até porque precisam dele para a propulsão da água. Há, sob o telhado mais alto, traços que podem corresponder a uma moenda, mas neste caso, mais provavelmente, seria uma moenda movida a bois, cavalos ou mesmo pelo braço escravo. Não seria, portanto, um engenho real. Talvez por isso interessasse ao artista mais a paisagem que a cena do processo produtivo que nos engenhos reais devia chamar atenção por sua magnitude.

Outro aspecto importante no óleo 31 é que o conjunto arquitetônico reunindo vários telhados conjugados - foge ao padrão dos engenhos reais compostos por dois telhados contíguos, um mais quadrado e fechado, ao lado de outro longitudinal e aberto onde ficam a moenda e a roda d'água. Como já ressalvei a impossibilidade de ver detalhes não permite afirmar que não seja um engenho, até porque há nele a indicação da existência de uma moenda. Mas por outro lado é possível afirmar que há sim, uma forte inadequação da imagem 31 ao padrão estabelecido por Post para seus engenhos de açúcar. Essa inadequação se explica tanto pela localização e composição do conjunto arquitetônico, quanto pela total ausência de escravos desempenhando as atividades usuais de um engenho de açúcar. Ao contrário dos outros engenhos, os escravos aí representados estão na estrada, conversando.

O quadro 31 foge ainda ao padrão dos engenhos de açúcar que se concentra nas cenas de trabalho. No lugar da concentração nas cenas de trabalho nas oficinas e no terreiro em frente, mostra dois ambientes diversos: mais ao fundo o conjunto arquitetônico sem escravos; e à frente um grupo de escravos conversando. São ao todo sete escravos, três homens e quatro mulheres. Os homens estão apenas conversando e cada mulher carrega um cesto cheio. Os cestos são grandes e fundos, bem diferentes das peneiras usadas pelas já mencionadas carregadoras de cana moída. O formato é comum nas representações da escravidão, sempre associados ao transporte de mandioca, legumes e pequenos animais. Assim, se a "maquinaria" do óleo 14 não corresponde à da "fábrica" de um engenho de açúcar, a cena apresentada no quadro 31 tampouco se aproxima das atividades usuais dos engenhos de açúcar onde a marca da presença humana é o trabalho nas oficinas.

Há aqui um ponto curioso a ser assinalado. As paisagens com escravos conversando e dançando nas estradas e caminhos mostram uma dimensão importante da sociabilidade escrava. Acredito que propositadamente Post os colocava sempre fora do enquadramento dos terreiros dos engenhos.

32 LAGO, Pedro Corrêa e LAGO, Bia Corrêa. (orgs.) Catálogo raisonné, p.163 (referente ao engenho 31). 
Por outro lado, nessas ocasiões há sempre uma presença destacada de mulheres carregando os tais grandes cestos. Essas mulheres iam para a roça muito cedo, por isso devem ter sido vistas pelo artista na volta, carregando na cabeça cestos cheios, pesados, por isso parando para descansar e conversar. A comparação dos óleos que mostram engenhos de açúcar com outros que mostram cenas de estradas e grupos de escravos confraternizando permite ainda intuir a distribuição do trabalho por sexo: nos engenhos de açúcar em sua maioria os trabalhadores são homens; já nas roças onde as mulheres arrancam e transportam a mandioca, predomina o trabalho feminino. Outra curiosidade é que, ao contrário de muitas descrições, as cenas de trabalho nas oficinas dos engenhos não retratam qualquer situação de violência, visão que certamente desagradaria aos compradores dos quadros do artista.

O destino destes cestos de mandioca pode ser desvendado pelo cruzamento de informações presentes nos quadros 31 e 14. Impossível de ser comida in natura devido às suas toxinas, a mandioca é processada mecanicamente em oficinas onde se produz a chamada farinha de mandioca. O que Post retrata no óleo 14 é uma cena de escravos numa oficina de beneficiamento de mandioca para preparo de farinha, ou em outras palavras, um engenho de farinha. Mais uma vez aí se constata a presença masculina, cabendo às mulheres a tarefa de arrancar, transportar e descascar a mandioca que vai ser, em seguida, ser transformada em farinha pelo trabalho engenhoso dos homens. O óleo 14 não mostra mulheres, elas estariam no interior da casa, descascando a mandioca trazida das roças. ${ }^{33}$

Segundo a moderna descrição da planta, a mandioca é conhecida cientificamente, como Manihot esculenta, Crantz, Enphorbiaceae, Dicotyledonae. A palavra parece derivar da língua tupi ("Mani" seria o nome da filha de um chefe; "oca" significa casa). A planta é um arbusto perene, resistente à seca, com raízes tuberosas de formato variado e em número de cinco a vinte. O caule (sem ramificação no período vegetativo) tem o pé ereto, de cor cinza ou prateada ou pardo-amarelada; as folhas são simples, contendo de cinco a sete lóbulos; as flores unisexuadas masculinas ou femininas; o fruto é uma cápsula (tricoca) com três sementes oleaginosas (parecidas com a da mamona) que se abre quando seco. As raízes são ricas em amido a apropriadas ao consumo alimentar. Existem dois tipos de mandioca, a "brava" e a "mansa". A primeira é consumida apenas sob a forma de farinha porque contém elementos tóxicos no látex, na casca da raiz e nas folhas.

33 Uma bela representação do interior de um engenho de mandioca do século XIX foi pintada por Modesto Brocos (1852-1936), pintor brasileiro de ascendência espanhola. O quadro Engenho de Mandioca é um óleo sobre tela de 1892. Mostra em primeiro plano mulheres sentadas descascando mandioca e ao fundo uma moenda (diferente do caititu) e um forno de torrar a farinha. Também Victor Frond tem uma fotografia, da qual se conhece apenas a litografia, de escravas descascando mandioca num terreiro, mas neste caso não há indicação de presença de uma casa de farinha. 
Para eliminar as toxinas é necessário amassar a raiz e prensar a massa até que escorra todo o látex. A segunda é também conhecida como macaxeira ou aipim, contém baixíssimo teor tóxico podendo ser consumida inteira. ${ }^{34}$

Da esquerda para a direita o óleo 14 mostra os três equipamentos usados no beneficiamento da mandioca. Depois de descascada pelas mulheres no interior da casa a mandioca um escravo colocada a mandioca inteira no primeiro equipamento, o caititu (ralador) enquanto outro move a roda para triturar uma a uma as raízes descascadas. Forma-se então uma massa que cai no coxo de onde é tirada e colocada em fôrmas de madeira para escorrer, o que correspondendo ao segundo equipamento. Atentar para uma pequena caixa com algo branco no interior: ali a massa é prensada para a retirada da "manipuera", nome vulgar dado ao ácido cianídrico (em algumas ocasiões usa-se também o tipiti, artefato indígena). Depois de seca, a massa é retirada das formas e os blocos endurecidos são amassados e passados na peneira. Por fim, já dissolvida, a farinha crua é levada ao terceiro equipamento mostrado, o chamado "forno", no formato de uma grande frigideira, onde vai ser torrada e depois ensacada. ${ }^{35}$ Assim sendo, este quadro inédito, é sem dúvida uma importante descoberta porque mostra um engenho de farinha, tema que não se repete no restante da (até agora conhecida) obra de Post nem na de outros artistas da época.

A farinha não era um produto comercializado na Europa e por isso geralmente relegado a segundo plano mesmo no universo colonial, onde era fartamente consumida. Os chamados "engenhos de farinha" ou "casas de farinha" sempre foram menosprezados tanto pela historiografia quanto pelos proprietários de terra que preferiam ser identificados como senhores de engenho (de açúcar) do que como produtores de farinha. O uso do termo "engenho de farinha" caiu em desuso na maior parte do Brasil e hoje se fala com mais freqüência em "casa de farinha". ${ }^{36}$ No século XVII os termos "engenho" e "casa", em certas circunstâncias, eram intercambiáveis, sendo também comum a expressão "casa de moer a cana", que aparece no texto do já citado Andreoni. ${ }^{37} \mathrm{O}$ desprestígio da farinha aparece na epígrafe deste texto e se repete, até o presente, talvez por isso sua representação pictórica atraia menos atenção do que a dos engenhos de açúcar.

34 Fonte: www.seagri.ba.gov.br/Mandioca.htm

35 O processamento da farinha é descrito em detalhes por ARAÚJO, Alceu Maynard. Brasil, Histórias, Costumes e Lendas. São Paulo: Editora Três, 2000.

36 O termo "engenho de farinha" ainda é corrente em Santa Catarina. ANDERMANN, Adriane Schroeder. Histórias de engenho: os engenhos de farinha de mandioca em Florianópolis, economia, cuidados com a produção, imagens (1917-1920). Florianópolis: Universidade Federal de Santa Catarina, 1996. (História, Dissertação de mestrado). No Rio de Janeiro pelo menos até o século XIX o termo era também corrente sendo depois substituído pela expressão "casa de farinha", mas a casa é menor e o trabalho ali realizado mais manual e não mecânico como no antigo engenho. "A casa de farinha só pode fazer pouca porção, não é? E o engenho não, o engenho pode durante um dia inteiro, pode fazer cinco, seis sacos de farinha por dia". (depoimento ao Museu do Folclore, Rio de Janeiro)

37 ANDREONI, João Antônio. Cultura e opulência do Brasil, p.182. 
No século XVII - e ainda hoje - as propriedades onde se plantava cana, mas não se processava o açúcar eram chamadas "fazendas" e não "engenhos"; os plantadores de cana eram partideiros e arrendatários, não "senhores de engenho". Já as propriedades produtoras de farinha eram chamadas engenhos, mas seus donos não eram senhores. A confusão se instala na medida em que, em muitos engenhos de açúcar, existiam também engenhos de farinha. $\mathrm{O}$ conjunto dos 34 óleos estudados mostrou que as oficinas dos engenhos de açúcar ocupavam os declives e que as casas grandes ficavam geralmente acima deles (20 casos, como indica o quadro anexo). Já os engenhos de farinha ficavam nas terras baixas. Segundo Andreoni todo engenho tinha terras boas e más e cada uma delas tinha sua serventia: as terras pretas e fortes, chamadas massapé, eram as melhores para a cana; as arenosas que misturam areia e salões não serviam para a cana, mas eram apropriadas ao plantio da mandioca e legumes. Nos 34 óleos analisados, seis deles não apresentam declives, apenas a várzea com conjuntos arquitetônicos pouco definidos, fazendo aventar que pudessem ser engenhos de farinha, e não de açúcar.

Numa sociedade baseada na hierarquia e na distinção social produtores de farinha eram socialmente relegados a segundo plano. Um exemplo do destaque dado aos senhores, tanto na ordem social quanto na visão que Post tinha dela, é o fato dele mostrar as chamadas casas-grandes sempre em plano superior em relação à oficina do engenho. Essa distribuição aparece nitidamente no óleo 47 que mostra a casa-grande, com dois andares no alto de uma colina, ao lado a capela e mais abaixo a oficina do engenho. Também outros engenhos mostram essa mesma formação. ${ }^{38}$ Já as "roças" ou "fazendas", ${ }^{39}$ nas quais se plantava mandioca, banana e outros produtos fogem a este padrão. O desenho 57, por ele intitulado "engenho", não mostra oficina, mas apresenta uma paisagem com nítidas elevações e com nome escrito de próprio punho. Pode-se daí concluir que o artista denominou engenho uma propriedade para a qual o termo se aplicava. Datado de 1638, portanto do ano seguinte de sua chegada, deve reproduzir a designação local para aquela propriedade, mesmo se nela não se veja o que Ihe justifica seu nome, ou seja, o engenho propriamente.

Como último detalhe, referindo-se ao óleo 31, os organizadores do Catálogo indicam a "raridade do reposoir duplo de vegetação densa". Segundo eles, este é um recurso "raramente usado por Post na segunda fase", quando "as árvores e arbustos não apresentam as características mais especificamente tropicais que Post usará exaustivamente na década seguinte (palmeiras, coqueiros, mamoeiros, etc.)". Sobre isso é curioso relembrar que a mandioca, uma planta eminentemente tropical e nativa

38 Os engenhos 17, 48, 50, 54, 57, 58, 59, 80, 104, 107, 108, 109, 114, 116, 118, 122.

39 Thomas Ender pintou em aquarela a Fazenda de Mandioca (1818) que pertenceu ao Barão de Langsdorff. 


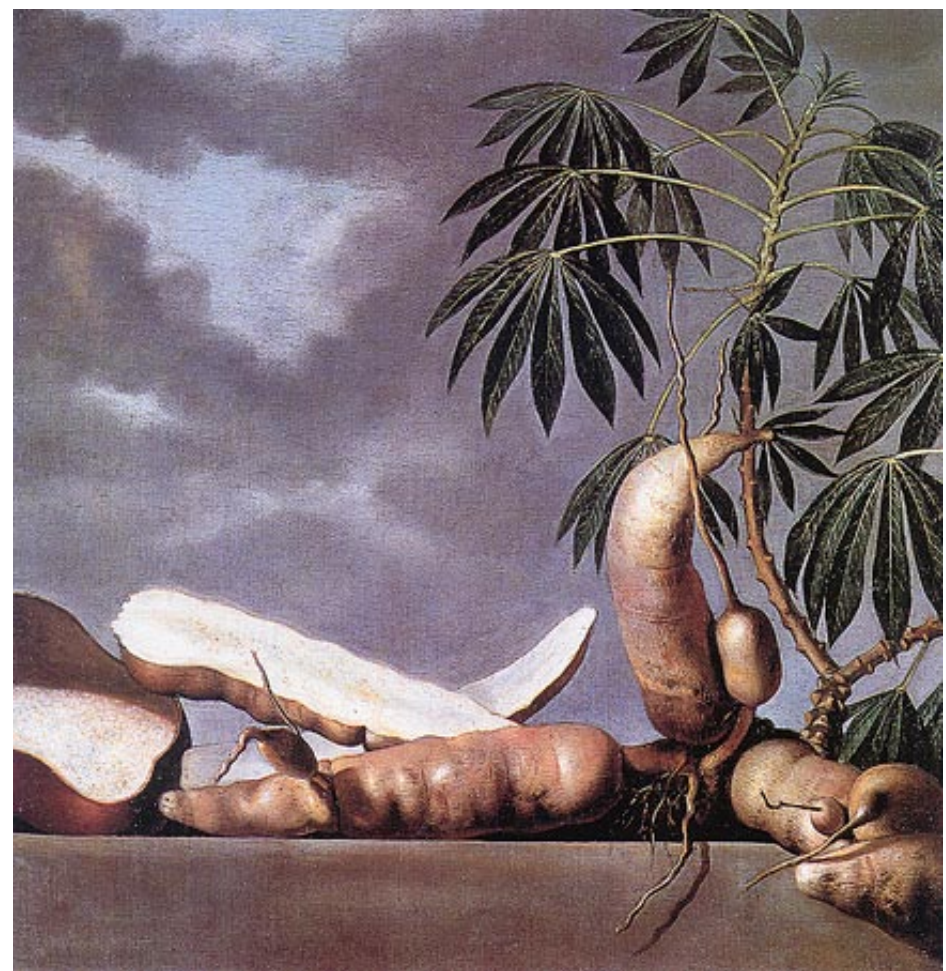

Imagem 4. Albert Eckhout. Óleo reproduzindo imagem da mandioca.

das Américas, é um arbusto perene, pé ereto e folhas simples, com entre cinco a sete lóbulos bem característicos. Pode ser arriscado tentar identificá-la na paisagem do óleo 31, pois o formato peculiar de suas folhas torna sua presença praticamente inquestionável na parte superior esquerda do reposoir do óleo 14, mostrado em detalhe na página 129 do Catálogo. Não foi possível encontrar uma representação da mandioca na obra de Post, mas ela foi alvo da atenção de Albert Eckhout (ca. 1610-ca.1666), pintor holandês contemporâneo de Post, que, como ele, residiu e trabalhou no Brasil Holandês nos tempos de Nassau. O óleo de Eckhout (Imagem 4) mostra a raiz e a folha da mandioca, uma planta de uso tão generalizado no Brasil e tão desconhecida para a maioria dos europeus. ${ }^{40}$

\section{Os engenhos de farinha no século XVII}

À diferença de outras mercadorias que circulavam tanto no Atlântico (os tecidos, o açúcar e as especiarias) quanto na própria colônia (as carnes, o

40 "Mandioca", tela de Albert Eckhout s/d. óleo sobre tela 93 × 93 cm Nationalmuseet (Copenhague, Dinamarca). Reprodução do óleo no texto. 
sal) a farinha não era considerada um produto comercial e sim um mantimento. ${ }^{41} \mathrm{~A}$ palavra mantimento é usada, por exemplo, por Andreoni no título do capítulo 1 do livro II: "Da escolha da terra para plantar canas-de-açúcar e para os mantimentos necessários e provimento do engenho". Andreoni mostra ainda, como foi indicado acima, a constante combinação no plantio dos dois produtos no interior dos engenhos de açúcar. Este mantimento acompanhou e alimentou a expansão marítima portuguesa do Atlântico ao Oriente e a vida no Brasil nos primeiros séculos da ocupação colonial. ${ }^{42}$

A produção regular de farinha começou com os jesuítas, quando estes construíram os primeiros aldeamentos para descimento de índios, descritos por Serafim Leite. ${ }^{43} \mathrm{~A}$ nova política, que substituía os missionários volantes por missões sedentárias se fazia de acordo com certas regras como situar os aldeamentos a uma pequena distância das povoações coloniais para Ihes servir de apoio quando necessário; dar prioridade a áreas litorâneas próximas a mangues e embocaduras de rios de modo a proteger o litoral contra ataques estrangeiros; treinar militarmente os índios para juntaremse às tropas de guerra armadas contra inimigos internos (índios bravos) e externos (a pirataria das nações européias). Instituída desde a criação do governo geral em 1548, essa política tomou vulto no governo do Mem de Sá (1557-1572), que sustentou o avanço do projeto catequista inaciano. Muito rapidamente seu consumo se generalizou mesmo nos engenhos reais e nas casas ricas.

Vários exemplos reforçam o caráter alimentar da farinha. Schwartz menciona o caso da Fazenda Saubara, localizada na região de agricultura de mandioca do Recôncavo Baiano. Note-se aqui o uso da palavra "fazenda" e não "engenho" para designar essa extensa e rica propriedade. A fazenda era propriedade da Santa Casa de Misericórdia, fornecendo farinha e outros produtos para o hospital, para outras instituições e para venda. ${ }^{44}$ Como mostra Stuart Schwartz a produção de farinha das vilas de Camamu, Cairú e Boipeba atendia à demanda da cidade de Salvador, dos engenhos de açúcar do recôncavo, das frotas que partiam para as Índias e África, das tropas e comboios que iam sertão adentro. Descrevendo a situação dos engenhos da Bahia o autor afirma que "o alimento básico da escravaria, bem como para os homens livres no Brasil, era a farinha de mandioca." Segundo ele, nos primeiros anos do século XVII, o crescimento dos engenhos e o uso intensivo dos escravos nas plantações de cana levaram a uma escassez de gêneros alimentícios e espalhou a fome entre os escravos que "comiam

41 ANDREONI, João Antônio. Cultura e opulência do Brasil.

42 Sobre a farinha na carreira da Índia ver LAPA, José Roberto do Amaral. A Bahia e a carreira da Índia. São Paulo/ Campinas: Hucitec/Unicamp, 2000.

43 LEITE, Serafim. História da Companhia de Jesus. Rio de Janeiro: Imprensa Nacional, 1943, vol.1.

44 SCHWARTZ, Stuart. Segredos internos. Engenhos e escravos na sociedade colonial 1550-1835. São Paulo: Companhia das Letras, 1995, p.126, 149, 83, 146, 304. 
tudo que lhes caísse nas mãos", inclusive os ratos dos canaviais, levando a Coroa a perceber a necessidade do plantio combinado de gêneros alimentícios. Em 1688 a legislação régia obrigou os produtores de açúcar do recôncavo baiano a plantar mandioca. ${ }^{45}$

Em artigo sobre o crédito e a circulação monetária na capitania do Rio de Janeiro, Jucá de Sampaio argumenta sobre a escassez de moeda metálica no Rio de Janeiro, na segunda metade do século XVII, fazendo surgir "moedas substitutas", ou seja, produtos de grande circulação que, na falta de dinheiro, entravam no circuito comercial no lugar do dinheiro sonante. Segundo ele, o açúcar, os tecidos - e em menor escala a farinha e a cachaça - foram utilizados como moedas substitutas no comércio atlântico. ${ }^{46}$

A leitura de textos de época, assim como toda a documentação coeva, já dá mostras da importância da farinha como produto básico do consumo colonial. Nos Diálogos das grandezas do Brasil a farinha foi tema de destaque, embora este fato não tenha a melhor análise por parte dos historiadores. Seu autor, Ambrósio Fernandes Brandão, foi feitor do rico cristão-novo Bento Dias de Santiago, portanto um conhecedor dos engenhos de açúcar da Bahia ${ }^{47}$ Os Diálogos foram editados por Capistrano de Abreu, que em sua Introdução lista os produtos mencionados nos diálogos terceiro e quarto: não faz menção à farinha, citando a mandioca como produto de consumo não comercializado, "a farinha se fazia diariamente, à maneira do pão". ${ }^{48}$ Já em seu livro sobre Portugal e o Atlântico no século XVII, Frédéric Mauro cita fartamente os Diálogos, observando que Brandônio (um dos interlocutores) afirmava ser a farinha o principal produto colonial. Apesar da constatação, tampouco o historiador francês avançou no estudo da produção e circulação da farinha, se concentrando no açúcar e no tabaco. ${ }^{49}$

Outro fator que dificulta a compreensão da importância da farinha na vida colonial diz respeito à terminologia a ela associada, fonte de equívocos, para a qual mais uma vez Brandônio nos traz pistas. Em primeiro lugar os Diálogos fornecem uma lista dos produtos que podem ser feitos com a mandioca e o modo de prepará-los. Esclarece ainda que existe uma variedade de farinhas feitas à base de mandioca, entre elas a farinha da terra (ou de pau), a farinha de guerra (a mesma farinha de pau mais seca, usada nas viagens por ser mais durável), e por fim a farinha puba (feita da macaxeira e própria para a feitura de beijus, tipo de biscoito também mais

45 SCHWARTZ, Stuart. Segredos internos, p.86, 353.

46 SAMPAIO, Antonio Carlos Jucá de. Crédito e circulação monetária na colônia: o caso fluminense, 1650-1750. Anais do V Congresso Brasileiro de História Econômica, Belo Horizonte/ABPHE, p.5-7, 12, 15, 2003.

47 O diálogo escrito em ca. 1618 têm dois interlocutores: Brandônio e Alviano. Brandônio é o próprio Ambrósio Fernandes Brandão. Ver GARCIA, Rodolpho. Aditamento. In: BRANDÃO, Ambrósio Fernandes. Diálogos das grandezas do Brasil, p.23.

48 Ver ABREU, Capistrano de Introdução. In: BRANDÃO, Ambrósio Fernandes. Diálogos das grandezas do Brasil, p.7-22.

49 MAURO, Frédéric. Le Portugal et l'Atlantique au XVIle siècle 1570-1670. Paris : École Pratique des Hautes Études, 1960, p.371. 
durável que a bolacha de farinha de trigo). Sobre a importância da farinha Brandônio informa:

Os mantimentos, de que se sustentam os moradores do Brasil, brancos, índios e escravos de Guiné, são diversos, uns sumamente bons, e outros não tanto; dos quais os principais e melhores são três, e destes ocupa o primeiro lugar a mandioca, que é a raiz de um pau, que se planta de estaca, o qual, em tempo de um ano, está em perfeição de se poder comer, e, por este mantimento se fazer de raiz de pau, Ihe chamam em Portugal farinha de pau. ${ }^{50}$

Já no final do diálogo primeiro, ao descrever a capitania do Rio de Janeiro, Brandônio diz:

Também neste Rio de Janeiro tomam porto as naus que navegam do Reino de Angola, onde carregam de farinha da terra, de que abunda toda esta capitania em grande quantidade e dali a levam para Angola, onde se vende por subido preço. ${ }^{51}$

Assim é que a farinha - chamada "de pau" em Portugal e "da terra" no Brasil - era produzida de norte a sul, no litoral e ao longo das estradas abertas pelo sertão adentro, e ainda era mandada para Angola, por "subido preço". ${ }^{52}$

Outro que nos fala da farinha é Gabriel Soares de Souza, que chegou ao Brasil em 1569. Senhor de engenho na Bahia, é o autor do Tratado descritivo do Brasil (1587), valioso testemunho do Brasil no século XVI. Segundo ele, a expressão "farinha-de-guerra" vem pelo costume dos índios:

Farinha-de-guerra se diz, porque o gentio do Brasil costuma chamar-Ihe assim pela sua língua, porque quando determinam de a ir fazer a seus contrários algumas jornadas fora de sua casa, se provem desta farinha, que levam às costas ensacada em uns fardos de folhas que para isso fazem, da feição de uns de couro, em que da Índia trazem especiaria e arroz; mas são muito mais pequenos, onde levam esta farinha muito calcada e enfolhada, de maneira que, ainda que Ihe caia num rio, e que the chova em cima, não se molha. ${ }^{53}$

O já mencionado Francisco de Brito Freire dá também detalhes sobre a farinha que chama igualmente "farinha de pau". Diz Brito Freire:

50 BRANDÃO, Ambrósio Fernandes. Diálogos das grandezas do Brasil, p.164.

51 BRANDÃO, Ambrósio Fernandes. Diálogos das grandezas do Brasil, p.59-60.

52 Na segunda metade do século XVII já há registros de plantações de mandioca ao longo das estradas percorridas pelas caravanas de escravos do interior de Angola até os portos do litoral. Ver MILLER, Joseph C. The Significance of Droughts, Diseases and Famine in the Agriculturally Marginal Zones of West-Central Africa. The Journal of African History, vol.23, n.1, p.17-61, 1982.

53 SOUZA, Gabriel Soares de. Tratado descritivo do Brasil em 1587. 
Esta farinha, que chamam comumente de pau, se faz de uma raiz como nabo, cujo nome é mandioca. A mandioca divide-se em perluxas e diversas espécies de outras plantas, com a mesma propriedade. Cresce de pequena estaca, ao igual das ervas que mais se levantam da terra, sazonando-se em menos de um ano. O sumo é mortalmente venenoso. O amego ralado e espremido coze no forno em vasos largos, desfeito como o cuscuz da Europa. Desta sorte lavram esta farinha que sustentando geralmente todo o Estado do Brasil, obram os índios de três castas: a que chamam uitinga, uieçacoatinga, uiatá. Fresca, a que se come no mesmo dia. Seca, a que dura seis meses. Torrada, a que passa de um ano. Avaliam-na pelo melhor mantimento depois do trigo; que também como de obreia às cartas e goma às voltas; e para bolos e caldos com nome de mingaus e beijus; no que se vem a apurar o mimoso pão daquela tosca farinha. ${ }^{54}$

Por fim, Barlaeus apresenta uma descrição que não se afasta das demais, mas oferece mais detalhes sobre o plantio e reforça no final o generalizado consumo da farinha, que era bem vista até mesmo pelas tropas holandesas:

O alimento dos naturais é a farinha, frutos vários e hortaliças. Preparam aquela com as raízes da mandioca. Esta apresenta ramos de nove folhas alternas, semelhantes ao cinco-em-rama ou pentafilão, à maneira de dedos. Não dá flores nem sementes. O caule lenhoso deita varas lenhosas. Em montezinhos de terra de 3 ou 4 pés de diâmetro, metem-se três ou quatro pedaços destas varas, deixando-se fora da terra até o meio. Formam-se e distribuem-se esses montinhos por espaçosíssimos campos. Estas varas lançam raízes debaixo do solo, das quais nascem e se multiplicam ramificações subterrâneas e radiciformes, da grossura de um braço, e às vezes de um côvado de comprimento conforme a qualidade do terreno. As raízes que os holandeses chamam doces, posto de grossura diferente da mandioca, botam, fora da terra, em 2 ou 3 rebentos, os quais, tornando-se lenhosos no oitavo, décimo ou duodécimo mês, servem de semente. A mandioca difere das nossas plantas só nisto: nada sai do fruto da mandioca para a sua propagação, e nas nossas o fruto é que gera as sementes, pelas quais se reproduzem. É a mandioca um alimento bastante forte e mais agradável do que o pão para os portugueses, índios e negros e até para os nossos soldados. ${ }^{55}$

O curioso é que tanto Brito Freire quanto Barlaeus falam da importância da farinha, mas descrevem apenas a mandioca. Nenhum deles descreve as "oficinas" ou "engenhos" de farinha, seja da crua, seja da torrada, que dura mais de um ano e pode ser levada para a guerra, embarcada nos navios ou simplesmente guardada. Esta é a grande importância histórica do óleo 14 de Frans Port: oferecer uma imagem detalhada do processo de produção da farinha no Brasil, em meados do século XVII. Resta saber se alguns dos seis "engenhos" situados na várzea e vistos de longe, ou mesmo o 31 com

54 FREIRE, Francisco de Brito. Lusitânia Brasílica, p.129.

55 BARLÉU, Gaspar. História dos feitos recentemente praticados, p.137. 
sua roda entrevista nas pinceladas do artista eram pequenos engenhos de açúcar ou engenhos de farinha, como o mostrado no óleo 14, ou quem sabe, maiores, nos quais como visto para descrições posteriores, a roda podia substituir o caititu.

\section{Conclusão}

Em Pernambuco, como na Bahia e no Rio de Janeiro, a importação de escravos africanos e sua dedicação à produção de açúcar, aumentaram a demanda de alimentos e especialmente a demanda da farinha que, mais que qualquer outro produto, era facilmente guardada e transportada, e ainda resistia aos atropelos do tempo e do clima. As culturas da cana e da mandioca coexistiram muitas vezes na mesma propriedade. A produção do açúcar dependeu da produção de farinha para alimentar escravos e toda a população dos engenhos. É a perspectiva de uma sociedade hierárquica que dá maior visibilidade ao açúcar em detrimento da farinha, ${ }^{56}$ fazendo com que homens de maior distinção não quisessem ver-se associados a um produto tão baixo. Um dos textos que quebra essa invisibilidade é, como foi visto, o do Diálogos das grandezas do Brasil. Mas se Brandônio descreve a farinha e suas qualidades, Alviano - o segundo interlocutor - a rebaixa, rebaixando o Brasil: "quando querem vituperar o Brasil, a principal coisa que the opõem de mal é que nele come-se farinha de pau". ${ }^{57}$

Essa perspectiva da degradação da farinha atuou sobre Post e seus compradores. Ao contrário de seus famosos engenhos de açúcar, o óleo 14, quem sabe na época chamado "casa de fazer farinha", se tornou visível e sobreviveu ao tempo e ao desprezo de todos. Teria, quem sabe, ficado com a família justamente porque para ele não foram encontrados compradores. Quase quatrocentos anos mais tarde, arrisco dizer que, para os historiadores, um dos grandes méritos de Post foi ter representado um engenho de farinha dos tempos do Brasil holandês.

56 Faço aqui uma analogia à análise sobre a visibilidade e os meios visuais do barroco desenvolvida por Maraval no "Apêndice" de seu livro. Ver MARAVAL, José Antônio. A cultura do barroco. São Paulo: EDUSP, 1997, p.389-405.

57 BRANDÃO, Ambrósio Fernandes. Diálogos das grandezas do Brasil. Salvador: Progresso, 1956. 


\section{Anexo 1: Legenda dos engenhos de Frans Post no Catálogo}

\begin{tabular}{|c|c|}
\hline \multicolumn{2}{|r|}{ Óleos } \\
\hline 14 & Engenho (1651) \\
\hline 17 & Engenho (1652) \\
\hline 20 & Paisagem de várzea com engenho (1652) \\
\hline 29 & Engenho (s/d) (fotografia) \\
\hline 30 & Paisagem pluvial com engenho (1656) \\
\hline 31 & Paisagem de várzea com engenho (1656) \\
\hline 37 & Paisagem de várzea com engenho (1658) \\
\hline 38 & Paisagem de várzea com engenho (1658) \\
\hline 43 & Engenho no Ceará (s/d) \\
\hline 45 & Engenho com cachoeira (1659) \\
\hline 47 & Engenho (1660) \\
\hline 48 & Engenho (1661) \\
\hline 50 & Engenho (1661) \\
\hline 54 & Engenho $(\mathrm{s} / \mathrm{d})$ \\
\hline 56 & Engenho (s/d) \\
\hline 57 & Engenho (s/d) \\
\hline 58 & Engenho (s/d) \\
\hline 59 & Engenho (s/d) \\
\hline 75 & Paisagem de várzea com engenho (1664) \\
\hline 76 & Paisagem de várzea com engenho (1665) \\
\hline 78 & Engenho (166[5]) \\
\hline 80 & Engenho (166[ ]) \\
\hline 104 & Engenho (1667) \\
\hline 107 & Engenho (s/d) \\
\hline 108 & Engenho (s/d) \\
\hline 109 & Engenho (1668) \\
\hline 112 & Engenho (s/d) \\
\hline 114 & Engenho (s/d) \\
\hline 116 & Engenho $(\mathrm{s} / \mathrm{d})$ \\
\hline 118 & Engenho (s/d) \\
\hline 122 & Paisagem com engenho (s/d) \\
\hline 127 & Paisagem de várzea com engenho (s/d) \\
\hline 128 & Paisagem de várzea com engenho (s/d) \\
\hline 131 & Engenho com torre $(\mathrm{s} / \mathrm{d})$ \\
\hline
\end{tabular}

\section{Desenhos}

\begin{tabular}{l|l} 
D21 & Engenho de duas rodas movido por bois $(1650)^{*}$ \\
D54 & Engenho com rodas movidas pela água** $(\mathrm{s} / \mathrm{d})$ \\
D57 & Engenho Maratapasipe (1638)
\end{tabular}

* Duas parelhas de quatro bois em cada moenda. Engenho grande, todos os outros são de uma moenda movida por uma roda d'água.

** Único caso de mulher vestida com pano à moda caribenha; único caso de mulher na moenda também vestida com pano. 


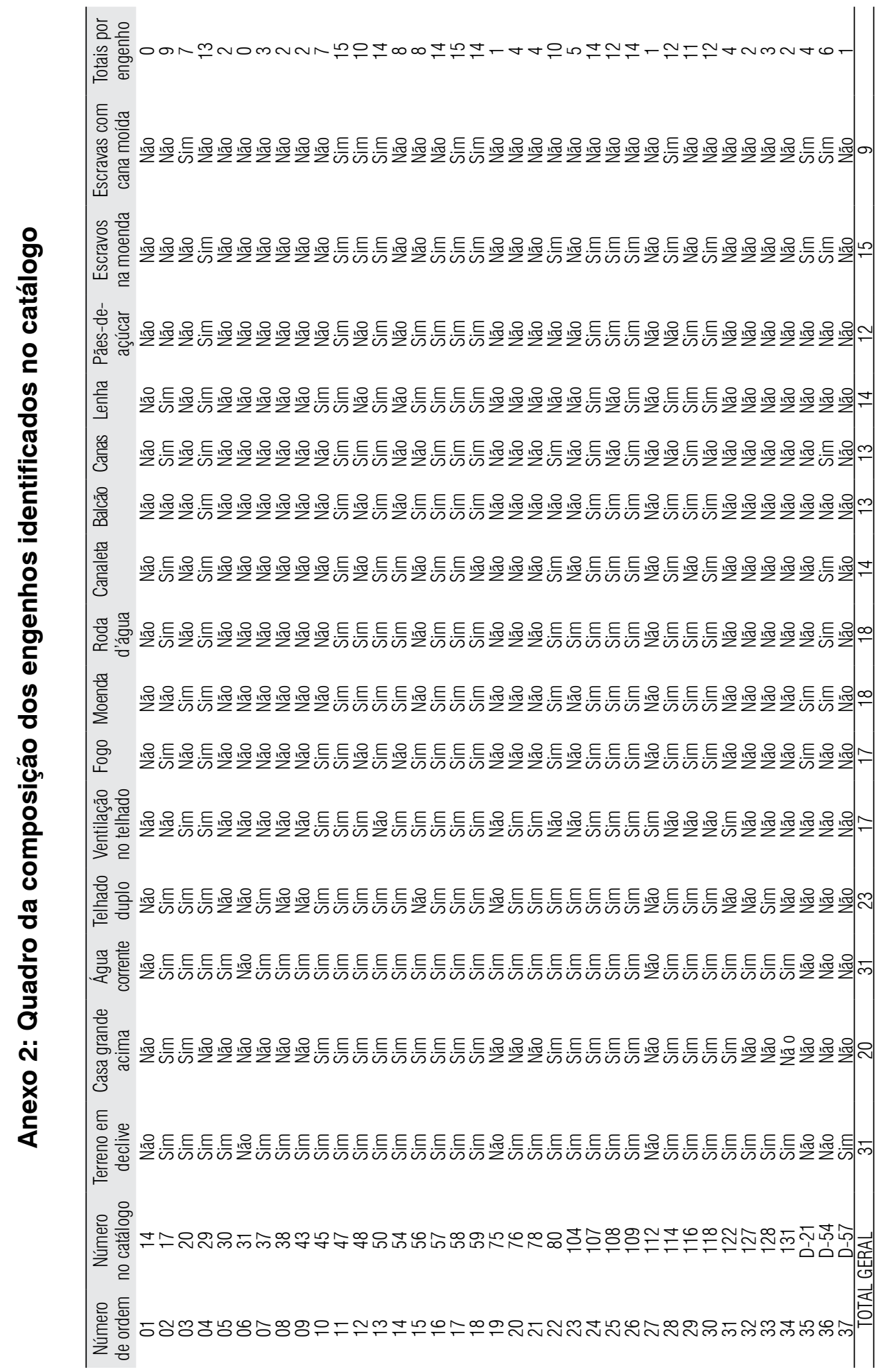

